\title{
EHMTI-0391. Use of telemedicine in the management of headache: a new tool between general practitioners and neurologists
}

\author{
E Murillo Espejo*, MC González Oria, MM Sánchez Calle, A Martínez García, F Núñez Benjumea, \\ D Jiménez Hernández
}

From 4th European Headache and Migraine Trust International Congress: EHMTIC 2014

Copenhagen, Denmark. 18-21 September 2014

\section{Introduction}

Headache is the most common neurological disorder seen by general practitioners (GPs) and neurologists. We propose the use of telemedicine system to evaluate patients with headache. This system will provide direct contact among GPs, Neurologists and patients, avoiding referal to the speciality clinic.

\begin{abstract}
Aims
Evaluation of telemedicine system in the assessment of patients suffering from headache, considering technical and assistance quality of care, delay in providing care, efficacy and patient's satisfaction.
\end{abstract}

\section{Methods}

We evaluated 15 patients with headache (13 women and 2 men, average age 36 years) by telemedicine system. Patients first evaluation was done by GPs and afterwards the same patients were evaluated by Neurologists using this system.

\section{Results}

Migraine was diagnosed in $86.7 \%$ of patients, and tensional headache in $13.3 \%$. In $53,3 \%$ of patients GPs and Neurologists made the same diagnosis. Neuroimaging studies were obtained in 3 patients, and the results were given to the patients using this system. The waiting time to be evaluated by Neurologists was 11 days. $80 \%$ of patients felt comfortable using this system, and $47 \%$ thougth it was better than face-to-face consultation. $66.7 \%$ of patients thought they could save time using this system and $100 \%$ will highly recommend it.

\section{Conclusions}

Our preliminary results showed that telemedicine system could be an useful and effective tool in the management of patients with headache between GPs and Neurologists. It will reduce the waiting time and it will provide the chance of a shared evaluation by GPs and Neurologists.

No conflict of interest.

Published: 18 September 2014

doi:10.1186/1129-2377-15-S1-J9

Cite this article as: Espejo et al:: EHMTI-0391. Use of telemedicine in the management of headache: a new tool between general practitioners and neurologists. The Journal of Headache and Pain 2014 15(Suppl 1):J9.
Submit your manuscript to a SpringerOpen ${ }^{\bullet}$ journal and benefit from:

- Convenient online submission

- Rigorous peer review

- Immediate publication on acceptance

- Open access: articles freely available online

- High visibility within the field

- Retaining the copyright to your article

C 2014 Espejo et al; licensee Springer. This is an Open Access article distributed under the terms of the Creative Commons Attribution License (http://creativecommons.org/licenses/by/2.0), which permits unrestricted use, distribution, and reproduction in any medium, provided the original work is properly cited. 